Western University Scholarship@Western

1978

\title{
A Theory of Development Controls in a "Small" City
}

Mark Frankena

David T. Scheffman

Follow this and additional works at: https://ir.lib.uwo.ca/economicsresrpt

Part of the Economics Commons

Citation of this paper:

Frankena, Mark, David T. Scheffman. "A Theory of Development Controls in a "Small" City." Department of Economics Research Reports, 7824. London, ON: Department of Economics, University of Western Ontario (1978). 
RESEARCH REPORT 7824

A THEORY OF DEVELOPMENT CONTROLS

IN A "SMALL" CITY

\author{
by \\ Mark Frankena \\ and \\ David Scheffman
}

June, 1978 
A THEORY OF DEVELOPMENT CONTROLS IN A "SMALL" CITY

\author{
Mark Frankena \\ Associate Professor \\ David Scheffman \\ Associate Professor \\ Department of Economics \\ University of Western Ontario \\ London, Ontario N6A 5C2 \\ Canada
}

June 1978 


\section{A THEORY OF DEVELOPMENT CONTROLS IN A "SMALL" CITY}

Mark Frankena

David Scheffman

ABSTRACT

This paper analyzes the implications of an institutional structure in which current residents of an urban area have the power to exercise control over the level and pattern of new residential development. We develop a general equilibrium spatial model of a "sma11" urban area in which the current residents can control new residential development through a zoning policy determined by majority vote. The current residents are modeled explicitly as home owners, and are allowed to be arbitrarily different in tastes and endowments. The urban government is assumed to provide a public good for its residents, the level of which is also determined by majority vote.

The "optimal" development control policy from the point-of-view of a particular current resident is determined and the allocation resulting from a majority vote of the current residents is described. We describe and analyze the resulting allocation when the public good is financed by a "head tax", and when it is financed by a property tax. We focus on the use of zoning to control development and we distinguish two types of zoning: 1) "aggregate zoning", which designates what land can be developed; and 2) lot- and house-size zoning. Such zoning is usually termed "flscal" zoning in the 11terature. We show that the optimal development control policy from the point-of-view of a particular current resident is always independent of his preferences (but not necessarily of his endowment). Somewhat surprisingly, perhaps, the ability of the current residents to control the size of the market, is not, itself, a source of market fallure. 
First best optimality will always require restrictive zoning. Any distortion from first best optimality is the result of the inefficiency of the tax system, not of exercised market power. We show that deviations from first

- best optimality may require "leapfrog" development, thus providing a possible explanation for this common urban phenomenon. 


\section{Introduction}

In recent years there has been an increasing amount of discussion in the economics, geography and legal literature, of the land use controls exercised by urban governments. ${ }^{1}$ This discussion is evidently largely in response to a perceived tightening of such controls by urban governments all across North America. ${ }^{2}$ Although there are several issues that arise under the general topic of urban land use controls, in this paper we will be concerned with the implications of the fact that the current residents of an urban area can generally control the level of new residential development through planning and zoning controls. We w111 assume the absence of externalities and congestion (which would, themselves, provide a case for some types of development control), in order to focus on the inherent potential "monopoly power" which the current residents may be able to exercise in the housing market.

This is an issue which has received very little attention in the economics literature, despite the fact that it has been widely claimed (especially by the development industry) that the exercise of monopoly power by urban governments has been a contributing factor in the urban real estate boom experienced in most of North America in the seventies. ${ }^{3}$ Two recent papers which address the issue of urban governments' potential monopoly control of development are White [1975], and Hamilton [1978].$^{4}$ The paper by White is concerned with the incentives created by property taxation for current residents to control new residential development. In the Hamilton paper, it is argued that since municipalities face a downward sloping demand for labour, they face a downward sloping demand for housing, which it is in the interests of the current residents to exploit. Hamilton tests this conjecture empirically for 
a sample of SMSA's, and argues that "Interurban housing-price variations of as much as $50 \%$ may be due to this phenomenon".

The previous literature on development controls has been deficient in three respects. First, a model which explains the decision-making of the current residents, and how such decision-making determines development control policies has not been developed. Second, the effects of such policies have not been fully analyzed in the context of a general equilibrium spatial model. Finally, the welfare implications of such policies have not been adequately analyzed.

In this paper we develop a general equilibrium spatial model of an urban area in which the current residents can control new residential development through a zoning policy determined by majority vote. The urban government is assumed to provide a public good for its residents, the level of which is also determined by majority vote. The "optimal" development control policy from the point-of-view of a particular current resident is determined and the allocation resulting from a majority vote of the current-residents is described. We describe and analyze the resulting allocation when the public good is financed by a "head tax", and when it is financed by a property tax. We will focus on the use of zoning to control development and we will distinguish two types of zoning: 1) "aggregate zoning", which designates what land can be developed; and;2) lot- and house-size zoning. Such zoning is usually termed "fiscal" zonfing in the literature.

The main results of our analysis are:

1. The zoning policy chosen by the current residents depends critically on the tax system;

2. The optimal zoning policy (from the point of view of the current residents), and the Pareto optimal zoning policy are always independent of the preferences of the current residents; 
3. When public good expenditures are financed by a head tax, the current residents will always be unanimous on the optimal zoning policy;

4. A property tax system creates incentives for lot- and housesize zoning. With a property tax, "optimal" aggregate zoning and "optima1" lot- and house-size zoning may require "leapfrog" development, thus providing a possible explanation for this common urban phenomenon.

5. The Pareto optimal city requires aggregate zoning, and lotsize zoning. Constrained Pareto optimality (where only aggregate zoning is possible) may require "leapfrog" development.

6. Assuming a "utility-taking" city (which is the model considered by Hamilton), the exercise of monopoly power by the current residents is not,itself, a source of market fallure. Rather, market failure, when it occurs, is the result of distortions created by the tax system.

In Section II of the paper a simple model is developed, which clarifies the major issues and exhibits some of the main results. In Section III a more general model is developed. The results derived from the simple model of Section II are shown to generalize, and the allocations resulting from various tax systems are described and analyzed. In Section IV, the efflciency properties of the allocations are determined, and constrained and unconstrained efficlent allocations are derived. 
II. A Simple Mode1 of Fiscal Zoning

As our point of departure, we will start with a simplified circular city model of residential location. 5 The residents of this city consume

a composite consumption good, a public good, and one unit of 1and. We will distinguish two groups of consumers : current residents, and potential residents. The current residents own the unit of land they reside on. For simplicity, we take the central business district (CBD) to be the point $(0,0)$. All residents of the city work in the CBD and therefore must commute there daily. The yearly wage for all residents is $W$, and the yearly conmuting costs for a resident living at distance $x$ from the CBD is $t(x)$. We assume that non-wage income arising from the production activities in the CBD is earned by non-residents (or that labourers are paid their average product).

\section{A. Current residents}

A typical current resident living at distance $x$ from the CBD owns and resides on one unit of land. His preferences depend on his consumption of the composite consumption good, $C$, the public good, $G$, and (because of a bequest motive) on the value of his assets, which includes the value of his land $p(x)$, (and on his consumption of land, which is fixed at one unit). Therefore we w111 write the preferences of a particular current resident, "Mr. $j^{\prime \prime}$, as $V^{j}\left(C, G, p(x)+A^{j}\right)$ where $\mathrm{A}^{j}$ is non-land assets. (Notice that the preferences of current residents are not assumed to be identical.) The budget constraint for Mr. $j$ is $\mathrm{ctt}(\mathrm{x})+\mathrm{T}^{j}(\mathrm{x})=\mathrm{W}^{j}$, where $\mathrm{W}^{j}=\mathrm{W}+\mathrm{Y}^{j}$, and $\mathrm{Y}^{j}$ is non-wage income, $T^{j}(x)$ is the yearly tax paid by Mr. $j$ (levied to pay for $G$ ), and the price of $C$ is taken to be unity. Therefore we can write the preferences of Mr. $j$ as

$$
v^{j}\left(W^{j}-t(x)-T^{j}(x), G, p(x)+A^{j}\right) \text {. }
$$


We assume that moving costs are such that Mr. j does not choose to change his location in the city. We assume that the urban government of this city controls the zoning over all land within distance $\bar{x}$ of the CBD, where $\bar{x}$ is such that $W-t(\bar{x})=0$. The current residents, through majority vote, determine the level of $G$ and the land which can be used for urban residential use.

The land in the city not occupied by the current residents is assumed to be owned by absentee landlords. We assume that the current residents own and reside on the land within distance $\widetilde{x}$ of the $C B D$, so that the land between $\mathbb{x}$ and $\bar{x}$ of the CBD is initially undeveloped。

\section{B. Potential Residents}

We assume that there are a large (at least $\pi \bar{x}^{2}$ ) number of identical ${ }^{7}$ potential residents of the city. Any potential resident who is allowed to reside in the city will, by assumption, consume one unit of land. Therefore, we w1ll write the utility function of one of these identical consumers as $U(C, G)$. The budget constraint of one of these consumers, if he is allowed to live at distance $x$, is $C+r(x)+t(x)+T(x)=W$, where $r(x)$ is the rent per unit of land at distance $x$ and $T(x)$ is the tax levied on such consumers living at distance $x$. Therefore we can write the utility function of the Identical potential residents as

$$
U(W-r(x)-t(x)-T(x), G) \text {. }
$$

These identical consumers can each, by assumption, attain a utility level of $\bar{U}$ by residing elsewhere. Therefore for any of these potential residents to live in the city, $r(x), T(x)$ and $G$ must be such that

$$
U(W-r(x)-t(x)-T(x), G) \geq \bar{U}_{0}
$$

If there is free competition among potential residents for any vacant residential lots in the clty, since there are a large mumber of potential residents the constraint in (3) will be binding. Therefore, we can derive the bid-rent gradient of potential residents from (2), yielding : 
(4)

$$
r(x)=W-t(x)-T(x)-C(G)
$$

where $C(\theta)$ is such that $U(C(G), G)=\bar{U}_{\text {. }}$

\section{Determination of $G$ and zoning when $G$ is financed by a head tax}

We are going to assume a static world, where preferences and the parameters of the model $(W, t(x), e t c$.$) are constant over time. The urban govern-$ ment must determine the level of $G$ and the zoning policy. We assume these decisions are the result of a majority vote of the current residents. For techntcal simplicity we will assume that the chosen level of $G$ and zoning decisions of the current urban government fix $G$ and the universe of residential land for all time. Thus we can think of $G$ as the services of an infinttely durable public capital good which is purchased by the current urban government.

When a current resident eventually sells his lot, he sells it to one of the potential residents or to a landlord who will then rent it to one of the potential residents. Similarly, the only purchasers of vacant land zoned for residential use are potential residents or landlords. Therefore, the value of a unit of residential land at distance $x$, assuming a constant interest rate of 1 , is

$$
p(x)=(1 / 1) r(x)
$$

In this section we assume that $G$ is financed by a head tax. We assume that one unit of $G$ costs one unit of numeraire per year so that the tax system is given by:

$$
\text { (6) } \quad T^{j}(x)=T(x)=G / N
$$

where $\mathrm{N}$ is the total number of residents (current plus migrants) in the city. Because each resident consumes one unit of land 
(7)

$$
N=2 \pi \int_{0}^{x *} x d x=\pi x^{*}
$$

where $x^{*}$, the boundary of urban development, is determined by zoning. We assume that the yearly wage, $W$, is a function of the number of workers (residents) so that

$$
W=W(N),
$$

where we will assume $W^{2}<0^{8}$ (our conclusions are not affected if $W^{\prime}>0$ for "small" N). Now, from (4)-(8), land rents and prices are determined, given $G$ and $x^{*}$,
a) $r(x ; x *, G)=W\left(\pi x *^{2}\right)-t(x)-G / \pi x *^{2}-C(G)$

(9)

b) $p\left(x ; x^{*}, G\right)=r\left(x ; x^{*}, G\right) / i$

Let the opportunity cost rental rate (e.g., return in agriculture) on land be $\bar{r}$. Then the boundary rent condition in the city is

$$
r\left(x^{*} ; x^{*}, G\right) \geqq \bar{r}
$$

The optimal G and city size from the point of view of a current resident, Mr. $j$, who resides at $x$, is found as the solution of the problem:

$$
\max _{\{x *, G\}} V^{j}\left(W^{j}\left(2 \pi x *^{2}\right)-t(x)-G / \pi x *^{2}, G, \frac{1}{i} r(x ; x *, G)+A^{j}\right)
$$

subject to $r\left(x^{*} ; x^{*}, G\right) \geqq \bar{r}$.

The first order conditions for (10) are
a) $\mathrm{V}_{\mathrm{C}}^{j}\left[2 \pi \mathrm{x} * \mathrm{~W}^{2}+2 \mathrm{G} / \pi \mathrm{x} *^{3}\right]+\mathrm{V}_{\mathrm{A}}^{\mathrm{j}} \mathrm{r}_{\mathrm{x} *}(\mathrm{x})+\lambda \mathrm{r}^{\prime}\left(\mathrm{x}^{*}\right)=0$
b) $v_{C}^{j}\left(-\frac{1}{\pi x^{*}}\right)+v_{G}^{j}+v_{A}^{j} r_{G}(x)+\lambda r_{G}\left(x^{*}\right)=0$

c) $r\left(x * ; x^{*}, G\right) \geqq \bar{r}$,

d) $\lambda[r(x * ; x *, G)-\bar{r}]=0$

(We assume that $x^{*}>\tilde{x}_{\bullet}$ ) 
where $r_{x *}(x)=\partial r(x ; x *, G) / \partial x *$,

$$
r^{\prime}\left(x^{*}\right)=d r\left(x^{*} ; x^{*}, G\right) / d x^{*}
$$

and

$$
r_{G}(x)=\partial r\left(x ; x^{*}, G\right) / \partial G
$$

We will assume that $x *$ and $G$ are determined sequentially in the following way: first $G$ is determined by a majority vote of the current residents; then given this $G, x^{*}$ is determined by a majority vote of the current residents. Let $G *$ be the level of $G$ chosen by majority vote. In another paper we fully analyze the determination of $G^{*}$, but from now on in order to focus on the optimal zoning policy we take $G^{*}$ as given. Now $x^{*}$ is to be determined. For Mr. $j$, the optimal $x *$ is found as the solution of the problem.

$$
\max _{\{x *\}} V^{j}\left(W^{j}\left(\pi *^{2}\right)-t(x)-G * / \pi *^{2}, G * ; \frac{1}{i} r(x ; x *, G *)+A^{j}\right)
$$

subject to $r\left(x^{*} ; x^{*}, G\right) \geqq \bar{r}$.

The solution for the optimal $x^{*}$ for $M r . j$ is given as the solution of

$$
\begin{aligned}
& \text { a) } \mathrm{V}_{\mathrm{C}}^{\mathrm{j}}\left[2 \pi \mathrm{x} * \mathrm{~W}^{8}+2 \mathrm{G} * / \pi \mathrm{x} *^{3}\right]+\mathrm{V}_{\mathrm{A}}^{\mathrm{j}} \frac{1}{\mathrm{i}} \mathrm{r}_{\mathrm{x} *}=0 \\
& \text { if } r\left(x^{*} ; x^{*}, G^{*}\right) \geqq \vec{r} \text {, and } x^{*} \geqq \tilde{x} \text { (a11 current residents live within } \\
& \widetilde{x} \text { of the } C B D \text {, by assumption), }
\end{aligned}
$$

or b) the solution of $r\left(x^{*} ; x^{*}, G^{*}\right)=\bar{r}$, otherwise.

(In the rest of the analysis we will assume $x^{*}>x_{0}$ )

Let $x_{c}$ be the solution of $r\left(x_{c} ; x_{c}, G^{*}\right)=\bar{x}$. Then $x_{c}$ is the boundary of urban residence of a perfectly competitive city (1.e., a city with no zoning restrictions) Therefore, the solution in (14b) is to have the competitive city, 1.e., no zoning restrictions. 
Now let us examine (14a). By (4)-(7) we can write (14a)

$$
v_{C}^{j}\left[2 \pi x * w^{2}+2 G * / \pi x *^{3}\right]+\left(V_{p}^{d} / 1\right)\left[2 \pi x * w^{2}+G * / \pi x *^{3}\right]=0
$$

Since $v_{C}^{j}$ and $v_{p}^{j}$ are both positive, this becomes

$$
2 \pi x * W^{*}+2 G * / \pi x *^{3}=0, \text { or } W^{\prime}+G * / N^{2}=0,
$$

which is independent of preferences. 9

From (14)-(16) we get the following very interesting result:

Independent of the current residents preferences, they

w111 be unanimous in their choice of the optimal zoning policy. The optimal zoning policy is to restrict residential development to land within distance $x^{*}$ of the CBD, where $x^{*}$ is the solution of $(16)$, if $r\left(x^{*} ; x^{*}, G *\right) \geqq \bar{r}$. Otherwise the optimal zoning policy is to have no zoning.

To analyze the likelihood that the solution of (16) will have the property $r\left(x^{*} ; x^{*}, G^{*}\right) \geqq \bar{r}$, let us examine $r\left(x^{*} ; x^{*}, G^{*}\right)$. From (9),
a) $d r(x * ; x *, G *) / d x *=2 \pi x * W^{2}+2 G / \pi x *^{3}-t^{\prime}(x *)$

(17)

$$
\text { b) } d^{2} r\left(x * ; x^{*}, G *\right) / d x *^{2}=2 \pi W^{\prime}+4 \pi^{2} x *^{2} W^{\prime \prime}-\frac{6 G}{\pi x *^{4}}-t^{\prime \prime}\left(x^{*}\right)
$$

Assuming $t^{\prime \prime} \geqq 0, W^{\prime \prime} \leqq 0$ (which are not necessary for the second order conditions), $I\left(x^{*} ; x^{*}, G^{*}\right)$ is a concave function of $x^{*}$ and the determination of the competitive city is depicted in the following diagram (we have also assumed $W^{\prime}$ is bounded).

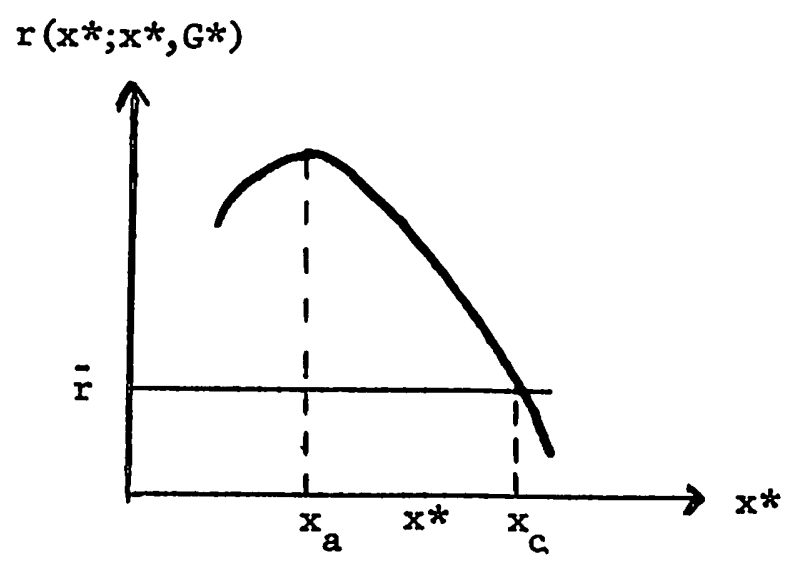

Figure 1 
At $x_{c}$, the boundary of the competitive city, $x\left(x_{c} ; x_{c}, G *\right)=\bar{r}$.

At $x_{a}, d r\left(x^{*} ; x^{*}, G *\right) / d x^{*}=0$, or

$$
2 \pi x_{a} W^{2}+2 G / \pi x_{a}^{3}-t^{\prime}\left(x_{a}\right)=0
$$

Therefore, the solution of $(16)$ is to the right of $x_{a}$. Since $N=\pi \times *^{2}$, we can write $(16)$ as

$$
W^{\prime}\left(N^{*}\right)+G / N *^{2}=0
$$

and the boundary rent condition becomes

$$
W\left(N_{c}\right)-G / N_{c}-t\left(\left(N_{c} / \pi\right)^{\frac{1}{2}}\right)-\bar{r}=0
$$

Rewriting (18) as

$$
-N^{*} W^{2}\left(N^{*}\right)-G / N^{*}=0 \text {, we see that in order for } N^{*}<N_{c} \text { (i.e., }
$$

$x^{*}\left(x_{C}\right)$, it must be the case that

$$
-N^{*} W^{*}\left(N^{*}\right)<W\left(N^{*}\right)-t\left(\left(\frac{N^{*}}{\pi}\right)^{\frac{1}{2}}\right)-\bar{r}
$$

A necessary condition for this to hold is that the total wage bill, $\mathrm{W} \cdot \mathrm{N}$, be increasing at $x^{*}\left(\right.$ i.e., $\left.W^{*}\right)+W^{\circ} \cdot N^{*}>0$ ). (Notice however from (18), if $W^{*} \equiv 0$, it is never the case that $x^{*}\left(x_{c}{ }^{\circ}\right)$

\section{E. Efficiency}

Although there seems to be an element of monopoly power in the model, In that the current residents can control the size of the "market" to their benefit (if $x^{*}<x_{c}$ ), the resulting allocation (for $x *<x_{c}$ ) 1s, given the tax system, efficient (i.e., Pareto optimal, given the tax system). This is because the resulting allocation maximizes the utility of the current residents, subject to the utility of migrants being at least $\bar{U}$ (and the tax system). (Notice this Is true even if the utility of the current residents does not depend on the value of their lots!) However, as we will see in Section IV, the optimal zoning 
policy will not generally be first best Pareto optimal, because the tax, itself, introduces a distortion.

The competitive allocation is not efficient in the case $x^{*}<x_{c}$ because the migrants do not take into account their effect on wages and taxes. Even in the case $x^{*}>x_{c}$, the competitive allocation is inefficient, in that (given the head tax) it would pay the current residents to subsidize some migrants to live beyond $x_{c}$, by subsidizing their rent payments so that their total rent payments would be $\bar{r}$ per person. 
III. A More General Model of Fiscal Zoning

In this section we will abandon the fixed lot size assumption and also explicitly introduce housing in the model. We will compare the effects of flnancing $G$ by a head tax with a property tax system, and will develop a model of fiscal zoning.

\section{A. Housing}

We will assume that housing is produced under constant-returns-toscale using factors purchased from outside the city, and that housing can be measured by a scalar quantity, which we will denote $h$. Housing is assumed to be infinitely durable and that the costs of demolition preclude replacement. We will denote the price of a unit of housing by $P_{h}$. Then, given constant interest rate $i$, the annual rental fee for a unit of housing is iP $P_{h}$, which we will denote $\theta$.

A current resident, Mr. j, living at distance $x$ owns a house $\bar{h}^{j}(x)$, and a lot, $\bar{s}^{-j}(x)$. His utility function can be written:

$$
V^{j}\left(W^{j}-t(x)-T^{j}(x), \bar{s}^{-j}, \bar{h}^{j}(x), G,\left[r(x) \vec{s}^{j}(x)+\theta \bar{h}(x)\right] / i+A^{j}\right)
$$

The utility function of one of the identical potential residents is

$$
U(C, s, h, G) \text { 。 }
$$

Therefore the total bid-rent for Mr. I's lot is

$$
r(x) \bar{s}^{-j}(x)=W-t(x)-T(x)-\theta \bar{h}^{j}(x)-C\left(G, s^{-j}, \bar{h}^{j}\right)
$$

where $C\left(G, \bar{s}^{j}, \bar{h}^{j}\right)$ is such that

$$
U\left(C\left(G, \bar{s}^{j}, \bar{h}^{j}\right), \bar{s}^{j}, \bar{h}^{j}, G\right)=\bar{U} \text {. }
$$

For "new" lots and houses (built on previously undeveloped land), the bid-rent (per unit of land) is given as the solution for $r(x)$ of the equation 


$$
u(r(x), \theta, W-t(x)-T(x), G)=\bar{U},
$$

where $u()$ is the indirect utility function of a migrant. Using the properties of the indirect utility function, the lot size and house size at distance $x$ are

$$
\begin{aligned}
& \text { (a) } s(x)=-u_{r} / u_{W} \\
& \text { (b) } h(x)=-u_{\theta} / u_{W}
\end{aligned}
$$

As before, for simplicity we will assume that the current residents own and reside on the land within $\widetilde{x}$ of the $\mathrm{CBD}$. Let $\widetilde{N}$ be the number of current residents. From (25) and $(26), s=s(x ; G, N)$, for $x>\tilde{x}$. The amount of land in the ring with inner radius $x$ and outer radius $x+d x$ is $2 \pi x d x$. Therefore the number of people living in that ring is $2 \pi x d x / s(x ; G, N)$. Then given $G$ and $x *$, the boundary of the zoned city, the total number of people in the city is given as the solution of the equation

$$
N=\tilde{N}+2 \pi \int_{\tilde{x}}^{x^{*}} x d x / s(x ; G, N)
$$

and we will denote this solution as $N(x *, G)$.

\section{B. G financed by a head tax}

In this section we will assume that $G$ is financed by a head tax, so that $T^{j}(x)=T(x)=G / N$. As before, we will assume that $G$ is chosen Initially by majority voting to be at some level $G *$. Then the choice of the optimal $x *$ for current resident $\mathrm{Mr} 。 \mathrm{j}$ is the solution of the problem.

$$
\max _{\left\{x^{*}\right\}} V^{j}\left(W^{j}-t(x)-G * / N, \bar{s}^{j}, \bar{h}^{j}, G^{*},\left(r(x) \bar{s}^{-j}+\theta \bar{h}^{-j}\right) / 1+A^{j}\right)
$$

subject to:

$$
\begin{array}{ll}
\text { 1) } N=N\left(x^{*}, G^{*}\right) & \text { (given by }(27)) \\
\text { ii) } r\left(x ; N\left(x^{*}, G^{*}\right), G^{*}\right) & (\text { given by }(24) \text { and }(25)) \\
\text { iii) } r\left(x^{*} ; N\left(x^{*}, G^{*}\right), G^{*}\right) \geqq \bar{r}
\end{array}
$$


From (24),

$$
r_{N}(x) s^{-j}(x)=W^{2}+G * / N^{2}
$$

Let $S\left(I\left(X ; N, G^{*}\right), \bar{U}\right)$ be the Hicks-compensated demand for land. Then by (25)

and (26) $S\left(x\left(x ; N, G^{*}\right), \bar{U}\right) \equiv s(x ; G *, N)$. Therefore, from (27)

$$
N_{x^{*}}=\left(2 \pi x^{*} / \mathrm{s}\left(\mathrm{x}^{*} ; \mathrm{G}^{*}, \mathrm{~N}\right)\right) /\left[1+2 \pi \int_{\tilde{x}}^{\mathrm{x} *} \mathrm{xS} \mathrm{S}_{\mathrm{N}} \mathrm{dx} / \mathrm{s}^{2}(\mathrm{x})\right]
$$

where $\quad S_{N}=S_{r} x_{N}=S_{r}\left(W^{\prime}+G / N^{2}\right) / S$

Now the first order conditions for (28) can be written:

$$
\begin{aligned}
& \text { a) } V_{C}^{j}\left(W^{*}+G * / N^{2}\right) N_{X^{*}}+\frac{1}{i} v_{A}^{j}\left(r_{N} s^{j}\right) N_{x^{*}}=0 \\
& \text { if } r\left(x^{*} ; N\left(x^{*}, G^{*}\right), G^{*}\right) \geqq \bar{r} \text {, }
\end{aligned}
$$

or b) $x\left(x^{*} ; N\left(x^{*}, G^{*}\right), G^{*}\right)=\bar{r}$, otherwise.

Using (29), this can be written

$$
\begin{aligned}
& \text { a) }\left(v_{C}^{j}+\frac{1}{1} v_{A}^{j}\right)\left(W^{2}+G * / N^{2}\right) N_{x^{*}}=0 \\
& \text { if } r\left(x^{*} ; N\left(x^{*}, G^{*}\right), G^{*}\right) \geqq \bar{r},
\end{aligned}
$$

or b) $r\left(x^{*} ; N\left(x^{*}, G^{*}\right), G^{*}\right)=\bar{r}$, otherwise.

$$
\text { Since } \left.V_{C}^{j} \text { and } V_{A}^{j}>0,(32) a\right) \text { can be written }
$$

$$
W^{2}+G * / N^{2}=0 \text {, }
$$

which gives the same optimal population as Section II:

All that has changed from the simple model of Section II is the optimal city size (since the relationship between $N$ and $x^{*}$ is now given by (27), rather than $N=\pi x *^{2}$ ). In particular the unanimity and efficiency properties of optimal zoning under a head tax system are preserved in the more general model. Notice that under a head tax system, there is no incentive for lot- or housesize zoning. 


\section{G financed by a property tax}

Now we will consider the effects of changing the method of financing G to a property tax. We assume that the tax is levied on the market value of the house and lot. Therefore if current resident Mr. j owns a lot of size $\bar{s}^{j}$ and house of size $\bar{h}^{j}$, his property tax is $\tau\left(x(x) \bar{s}^{j}(x)+\theta \bar{h}^{j}(x)\right) / i$, where $T$ is the tax rate. Without loss of generality, we assume that no tax is levied on agricultural land. In this section we w111 assume only aggregate zoning 18 possible.

The total bid-rent for Mr. $j$ 's lot is

$$
r(x)^{-j}(x)=W-t(x)-\theta \theta^{-j}(x)-C\left(G, \bar{s}^{-j}, \bar{h}^{j}\right)
$$

and the bid-rent (per unit of land) for a "new" lot is given as the solution for $r(x)$ of the equation

$$
u(r(x), \theta, W-t(x), G)=\bar{U}
$$

As before, $s(x)$ and $h(x)$ are given by (26).

Let $\alpha(x)$ be the proportion of land zoned for development at distance $x$, and $R(\langle x(x)\rangle, G)$ be the total value of residential land and housing for a city with zoning, $\langle\alpha(x)\rangle$, and amount of public good, G. Then

$$
R\left(\langle\alpha(x)>, G)=\frac{1}{i}\left\{2 \pi \int_{0}^{x^{*}} \alpha(x) \operatorname{xr}\left(x ; N\left(x^{*}, G\right), G\right) d x+2 \pi \int_{0}^{x^{*}} \alpha(x) A h(x) x d x / s(x ; N, G)\right\}\right.
$$

Given $\alpha(x)$ and $G$, the tax rate, $T$, is given by $r=G / R(<\alpha(x)>, G)$

$$
\text { As before, we will assume that } G \text { is chosen initially by majority voting }
$$

to be at some level G* (we would expect the level to be different with the property tax). Then the choice of the optimal $x *$ for current resident Mr. $j$ is the solution of the problem

$$
\begin{aligned}
& \text { (37) } \max _{\{<\alpha(x)>, N\}} V^{j}\left(W^{j}-t(x)-(T / 1) r(x) s^{-j}(x)+\theta \bar{h}^{-j}(x)\right), \\
&\left.s^{j}, \bar{h}^{j}, G *,\left(1-\frac{\tau}{i}\right)\left(r(x) s^{-j}(x)+\theta \bar{h}^{-j}(x)\right) / i+A^{j}\right)
\end{aligned}
$$


subject to: i) $N=\widetilde{N}+2 \pi \int_{\tilde{x}}^{x^{*}} x \alpha(x) d x / s(x)$, where $s(x)=s(r(x), \theta, \bar{U})$

is the Hicks-compensated demand for land

ii) $r\left(x ; N\left(x^{*}, G^{*}\right), G *\right)$ (given by (34) and (35))

iii) $(1-\tau / i) r\left(x^{*} ; N\left(x^{*}, G^{*}\right), G^{*}\right) \geqq \bar{r}$

iv) $0 \leqq \alpha(x) \leqq 1$

Using (34),

(38)

$$
\begin{aligned}
W^{j}-t(x)-(\tau / i)\left(r(x) \bar{s}^{-j}(x)\right. & \left.\left.+\theta \bar{h}^{j}(x)\right)=(1-\tau / i)(r(x))^{-j}+\theta \bar{h}^{-j}(x)\right) \\
& +Y^{j}-C\left(G, \bar{s}^{-j}(x), \bar{h}^{j}(x)\right),
\end{aligned}
$$

and $Y^{j}, C\left(G, s^{-j}(x), \bar{h}^{j}(x)\right)$ are independent of $N$.

Therefore, the maximization problem (37), becomes

$$
\left.\max _{\{<\alpha(x)>, N\}}(1-\tau / i)(x(x))^{-j}(x)+\theta \bar{h}^{-j}(x)\right)
$$

which is independent of Mr. I's preferences.

By (34), given $N,\left(r(x) s^{-j}(x)+\theta^{-j}(x)\right.$ is determined. Therefore the solution of (39) can be described as a two-stage maximization problem:

1) Given $N$, minimize $\tau$ (i.e., given $N$ maximize $R(<\alpha(x)\rangle, G *$ ). The solution of this problem gives $R^{*}=R\left(N, G^{*}\right)$. 2) Then substituting $R(N, G)$ in (39), maximize (39) with respect to $N$.

The first-stage maximization problem can be posed as an optimal control problem in the following way. Let

$$
\Omega(x)=2 \pi \int_{\tilde{x}}^{x} z \alpha(z)[r(z)+\theta H(z) / S(z)] d z
$$

Then the first-stage maximization problem is 
(41)

$$
\begin{aligned}
& \max _{\{\alpha(x)\}} \Omega\left(x^{*}\right) \\
& \text { subject to } \\
& \text { i) } u(r(x), \theta, w-t(x))=\bar{U} \\
& \text { ii) } 0 \leqq \alpha(x) \leqq 1 \\
& \text { iii) } S(x)=S(r(x), \theta, \bar{U}), i . e_{.} \text {, the Hicks-compensated } \\
& \text { demand for land, } \\
& \text { iv) } \mathrm{H}(\mathrm{x})=\mathrm{H}(\mathrm{r}(\mathrm{x}), \theta, \bar{U}) \text {, i.e., the Hicks-compensated } \\
& \text { demand for housing, } \\
& \text { v) } 2 \pi \int_{\widetilde{x}}^{\bar{x}} \alpha(x) x d x / s(x)=N-\tilde{N} \\
& \text { vi) }(1-\tau) r\left(x^{*}\right) \geqq \bar{r} \text {. }
\end{aligned}
$$

Maximization problem (41) can now be posed as an optimal control problem with state variable $\Omega(x)$, control variable $\alpha(x)$, and dynamics (from (40))

$$
\Omega^{\prime}(x)=2 \pi x X(x)[x(x)+\theta H(x) / s(x)]
$$

The Hamiltonian for this problem is

$$
\text { (43) } \mathcal{H C}=\lambda[2 \pi x \alpha(x)(x(x)+\theta H(x) / S(x))]-\mu 2 \pi x \alpha(x) / S(x)
$$

where $\lambda>0$ is the costate variable corresponding to $\Omega$, and $\mu \geqq 0$ is the (constant) multiplier corresponding to constraint (41)v).

The first-order conditions for the maximization of the Hamiltonian with respect to the control variable require

$$
\begin{aligned}
& \text { i) } \alpha(x)=1, \text { if } \lambda[r(x)+\theta H(x) / S(x)]-\mu / S(x) \geqq 0 \\
& \text { ii) } \alpha(x)=0 \text {, otherwise. }
\end{aligned}
$$

The transversality condition determining $x *$ requires 
(45)

1) $\lambda\left[r\left(x^{*}\right)+\theta H\left(x^{*}\right) / S\left(x^{*}\right)\right]-\mu / S(x)=0$, if $(1-\tau / i) r\left(x^{*}\right) \geqq \bar{r}$,

or ii) $(1-\tau / 1) r\left(x^{*}\right)=\bar{r}$, otherwise.

If $\mu=0$, (45)ii) is binding, and all land is zoned for development. If $\mu>0$ and (45)i) holds, $x *$ is determined by (45)i), and $\alpha(x)$ is determined by (44)i)。

Equation (44)i) can be written

$$
\alpha(x)=1 \text { if } r(x) S(x)+\theta H(x) \geqq \mu / \lambda,
$$

1.e., land at $\mathrm{x}$ is zoned for development if the total bid-rent for a lot and

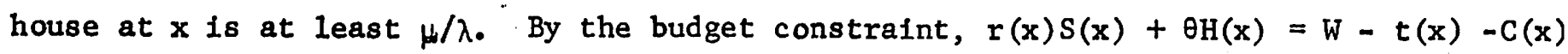
where $C(x)=C(r(x), \theta, \bar{U})$ is the H1cks-compensated demand for consumption. Differentiating this total bid-rent with respect to $x$,

$$
d / d x[r(x) S(x)+\theta H(x)]=-t^{\prime}\left(1+C_{r} / S\right)
$$

since (by $(25)) r^{\prime}(x)=-t^{8} / S(x)$, and $C^{\prime}(x)=C_{r^{\prime}}{ }^{\prime}$.

The sign of $C_{r}$ depends on preferences, so the sign of (47) is indeterminate.

The indeterminacy of the sign of (47) means that it may be the case that for some $\hat{x} \in\left(\tilde{x}, x^{*}\right), r(\hat{x}) S(\hat{x})+\theta H(\hat{x})<\mu / \lambda$, which would mean that for such $\hat{x}$, land at $\hat{x}$ is not zoned for development. In such a situation optimal zoning requires rings of undeveloped land strictly within the boundaries of development, which, in the popular terminology, we can term "leapfrog" development. ${ }^{10}$ This possibility arises because given any $N$, to maximize total property value ( $R$ ), the sum of total expenditures on land and housing per person should be maximized. Thus (46) requires the expenditure per person (not per unit of land) to be at least $\mu / \lambda$. Although land at $\hat{x} 18$ more valuable than land at $\hat{x}^{\prime}(>\hat{x})$, the total expenditure on land and housing per person at $\hat{x}$ may be less than at $\hat{x}^{\prime}$. By (47), a necessary condition for leapfrogging to occur is that $c_{r}<0$, i.e., consumption and land are net 
complements, or equivalently, that consumption falls with distance.

The solution of $(40)$ gives $\Omega(N)$. Now proceeding to the second stage of the maximization problem,

$$
R(N, G *)=2 \pi \int_{0}^{\tilde{x}} x(r(x) \vec{s}(x)+\theta \bar{h}(x) / \vec{s}(x)) d x+\Omega(N)
$$

The solution of (39) is given by the solution of

$$
\begin{aligned}
& \max (1-\tau / i)\left(r(x) s^{-j}(x)+\theta^{-j}(x)\right. \\
& \{N\} \\
& \text { subject to } \tau=G / R(N, G *), N \geqq \widetilde{N} .
\end{aligned}
$$

Using (34), the first-order conditions for this problem are

$$
(1-\tau / 1) W^{2}(N)+\left(\tau R_{N} / i R\right) \Lambda^{j}=0 \text {, or }(1-\tau / i) W^{\prime}(N)+\left(R_{N} / i R\right) T^{j}(x)=0 \text {, }
$$

where $\Lambda^{j}$ is the total bid-rent for Mr. $j$ 's property. An interior solution to (50) requires $\mathrm{R}_{\mathrm{N}}>0$.

Assuming a regular interior solution, using the second-order conditions it is easily seen that

$$
\partial N / \partial \bar{s}^{-j}>0, \partial N / \partial \bar{h}^{j}>0, \partial N /\left.\partial x\right|_{-s^{j}, \bar{h}^{j}}<0
$$

Therefore, current residents with more "valuable" properties prefer less

\section{restrictive zoning.}

Differentiating (48) with respect to $N$ using (34),

$$
R_{N}=W^{r} \tilde{N}+\Omega^{\prime}(N)
$$

Using (25), $r_{N}=W^{1} / S(x)$, so that $\Omega^{2}(N)$ can be written

$$
\Omega^{2}(N)=2 \pi W^{2} \int_{\tilde{x}}^{\bar{x}} \frac{\alpha^{*}(x)}{S(x)}\left[1+\theta H_{x}-\theta H(x) S_{r} / S(x)\right] d x+\mu
$$

Combining (52) and (53),

$$
R_{N}=W^{2} N+2 \pi W^{2} \int_{\tilde{x}}^{\bar{x}} \frac{\alpha^{*}(x)}{S(x)}\left[\theta H_{r}-\theta H(x) S_{r} / S(x)\right] d x+\mu
$$

Since $S_{r}<0$, and an interior solution to (49) requires $R_{N}>0$, if housing and land are net substitutes $\left(H_{r}>0\right)$, an interior solution to (49) 
requires $\mu>0$. In this case, using (44) and (45), the solution of (49) is likely to require restrictive zoning.

It is not possible to compare (33) and (50), even assuming $G *$ is the same and that the tax burden of the median voter under the property tax is equal to the head $\operatorname{tax}$ in (33). Therefore the relative restrictiveness of optimal zoning under the two-tax system is not determinate. As with the head tax, the optimal zoning policy is efficient, given the tax system, but the policy is not generally first best efficient because the tax introduces a distortion. Furthermore, as we will see in the next section, the property tax system creates incentives to introduce further distortions.

D. Lot- and house-size zoning when $G$ is financed by a property tax

When $G$ is financed by a property tax it is in the interests of the current residents to impose lot size and house size zoning on "new" residential development. This is the result of the fact that given any total number of people, $\mathrm{N}$, in the city, the tax paid by any current resident can be reduced by making total property value as large as possible for that level of population.

From (34), the total bid rent for Mr. $\mathrm{j}^{\prime \prime}$ 's lot and house is determined, given N. Therefore given any total population N, (and G*), Mr. j's welfare improves, the smaller is the tax rate, i.e., the larger is total property value. In the simple property tax model of the previous section, the choice of $x *$ determined $N$ and $R_{0}$ However, if $s(x)$ and $h(x)$ can be zoned by current residents, both $x *$ and $N$ can be chosen (subject to constraints).

The optimal fiscal zoning policy for Mr. I can be described by a twostage maximization problem: first maximize $R$, given $N$; then maximize $\mathrm{v}^{j}$ with respect to No The first-stage maximization problem is : 
(55)

$$
\{\alpha(x), s(x), h(x)\}^{\max } 2 \pi \int_{\widetilde{x}}^{\bar{x}} \alpha(x) x[r(x ; N, G *)+\theta h(x) / s(x)] d x
$$

subject to

$$
\begin{aligned}
& \text { i) } r(x ; N, G *, s, h)=[W-t(x)-\theta h(x)-C(G *, s(x), h(x))] / s(x) \\
& \text { ii) } 2 \pi \int_{\widetilde{x}}^{\bar{x}} \frac{\alpha(x) x d x}{s(x)}=N-\tilde{N} \\
& \text { iii) }\left(1-\frac{\tau}{1}\right) r(x ; N, G *, s, h) \geqq \bar{r}
\end{aligned}
$$

where $\alpha(x)$ is the proportion of land at $x$ zoned for development, $0 \leqq \alpha(x) \leqq 1$.

$$
\text { Let } \Omega(x)=2 \pi \int_{\widetilde{x}}^{x} \alpha(z) z[r(z ; N, G *)+\theta h(z) / 8(z)] d z \text {. Then }(55) \text { can be }
$$

posed as an optimal control problem with state variable $\Omega(x)$ and control variables, $(\alpha(x), s(x), h(x):$

$$
\left\{\alpha(x), s(x), h(x), x^{*}\right\}^{\Omega\left(x^{*}\right)}
$$

subject to i) $\left.\Omega^{\prime}=2 \pi \alpha(x) x\left[r\left(x ; N, G^{*}\right)+\theta h(x) / s(x)\right)\right]$

ii) (55) i) - iii)。

Using (34), the Hamiltonian for this problem can be written

$$
\begin{aligned}
\mathcal{H}= & \lambda 2 \pi \alpha(x) x[W-t(x)-C(G *, s(x), h(x))] / s(x) \\
& -\mu 2 \pi \alpha(x) x / s(x)+\gamma 2 \pi \alpha(x) x[(1-\tau / 1) r(x)-\bar{r}]
\end{aligned}
$$

where $\lambda$ is the costate variable corresponding to $\Omega$, and $\mu$ and $\gamma$ are the (nonnegative) multipliers corresponding to the constraints (55)if) and 1i1), respectively. Since the dynamics $((56) i)$ ) are not a function of the state variable, $\lambda$ is a constant, as is $\mu_{0}$

The first order conditions for maximization of the Hamlitonian with respect to the control variables are: 
(58)

$$
\text { 1) } \begin{aligned}
\alpha(x) & =1, \text { if } \lambda[r(x) s(x)+\theta h(x)]-\mu \geqq 0 \\
\alpha(x) & =0, \text { otherwise. }
\end{aligned}
$$

ii) $-\lambda\left(x(x) / s+C_{s} / s+\frac{\theta h}{2}\right)-\gamma(1-\tau / i)\left(\frac{r(x)}{s}+\frac{C}{s}\right)+\mu / s^{2}=0$, if $\alpha(x)=1$.

iii) $-\lambda C_{h} / s-\gamma(1-\tau / i)\left(\frac{C h}{s}+\theta / s\right)=0$, if $\alpha(x)=1$.

iv) $\gamma\left[(1-\tau / 1) r\left(x ; N, G^{*}\right)-\bar{r}\right]=0, \gamma \geqq 0$.

Since $\left.c_{h}<0,(58) i i i\right)$ requires $\gamma>0$ which means that

$$
(1-\tau / 1) x\left(x ; N, G^{*}\right)=\bar{r} \text {, for } x \text { such that } \alpha(x)=1 \text {. }
$$

Therefore optimal 1ot- and house-size zoning results in flattening the bid-rent gradient for developable land to $\bar{r} /(1-\tau / i)$, i.e., driving the bid-rent on land down to Its lowest possible value!

The transversality condition requires that the Hamiltonian be zero at $x *$, 1.e.,

$$
\lambda\left[\frac{\bar{r}_{s}\left(x^{*}\right)}{(1-\tau / 1)}+\theta h\left(x^{*}\right)\right]-\mu=0
$$

Therefore, as long as (55)ii) is binding (so that $\mu \neq 0$ ), $\lambda \neq 0$. From (60) we also see that $(\mu / \lambda)$ is the rent on a property (land plus house) at the outer boundary of development. Now, returning to (58)ili),

$$
-c_{h}=\frac{\gamma(1-\tau / i)}{\lambda+\gamma(1-\tau / 1)} \theta \text {, if } \alpha(x)=1 \text {, }
$$

from which we see that the marginal rate of substitution between housing and consumption is less than the price of housing. Therefore, given $s(x)$, optimal house-size zoning requires largex houses than would be freely chosen at price $\theta$. 


\section{Rewriting (58)ii)}

$$
-\left(r(x)+C_{s}\right)=\frac{1}{\lambda+\gamma(1-\tau / i)}\left[\frac{\lambda \Leftrightarrow h(x)}{s}-\mu / s\right] \text {, if } \alpha(x)=1 \text {. }
$$

From (58)1),

$$
\lambda \theta h(x)-\mu \geqq-\lambda \bar{r} s(x) /(1-\tau / 1)<0,
$$

so that the sign of $r(x)+C_{s}$ is indeterminate. Therefore optimal lot-size zoning may require either larger or smaller lots than would be freely chosen at price $r(x)=\bar{r} /(1-T / i))$, given $h(x)$. However, by $(60)$,

$$
\lambda \theta h\left(x^{*}\right)-\mu=-\lambda \vec{r} s\left(x^{*}\right) /(1-\tau / i),
$$

so that $-\left(r\left(x^{*}\right)+C_{S}<0\right.$. Therefore at the boundary of development, lot sizes (and house sizes) are larger than would be freely chosen at price $\bar{r} /(1-\tau / 1)$, given $h\left(x^{*}\right)$.

Let $\mathfrak{K}(x)=\mathfrak{H C} / 2 \pi x \alpha(x)$ (for $x$ such that $\alpha(x)=1$ ). Then

$$
\mathscr{H}(x)=\lambda[r(x)+\theta h(x) / s(x)]-\mu / s(x)+\tilde{\gamma}[(1-\tau / i) r(x)-\bar{r}]
$$

Since $\mathcal{I C}(x)$ is maximized with respect to $s(x)$ and $h(x)$, by the usual envelope relationship

$$
\mathfrak{H}^{2}(x)=-\lambda t^{\prime} / s-\tilde{\gamma}(1-\tau / t) t^{2} / s<0
$$

Finally, let us return to (58)i), which requires, (using (60)), that for land to be developed at distance $x$, the total bid-rent for a property (land plus home) at $\mathrm{x}$ be at least equal to the total bid-rent for a property at distance $x *$. Using (65) 
(67)

$$
\lambda[r(x) s(x)+\theta h(x)]-\mu=\mathfrak{H}(x) s(x) 。
$$

Differentiating with respect to $x$,

$$
d / d x\{[r(x) s(x)+\theta h(x)]-\mu\}=\mathscr{F} \mathfrak{C}^{\prime} s(x)+\widetilde{f} s^{\prime}(x),
$$

and we have shown that $\mathfrak{H}^{2}<0$. To determine the sign of $s^{2}(x)$, we must totally differentiate (58)ii)-iv). Multiplying by $s(x)$ and totally differentiating, we have

$$
\text { i) } \begin{aligned}
-(\lambda+\gamma(1-\tau / i)) C_{s s} d s-\left(\lambda+\gamma(1-\tau / i) C_{s h} d h\right. \\
-(1-\tau / i)\left(r+C_{s}\right) d \gamma=-(\lambda+\gamma(1-\tau / i)) t^{2} / s
\end{aligned}
$$

i1) $-(\lambda+\gamma(1-\tau / i)) c_{h s} d s-(\lambda+\gamma(1-\tau / i)) c_{h h} d h-(1-\tau / 1)\left(c_{h}-\theta\right) d \gamma=0$

iii) $-\gamma\left(x+C_{s}\right) d s-\gamma\left(\theta+c_{h}\right) d h=\gamma(I-\tau / i) t \cdot / s$

Solving for s',

(70) $s^{2}=\frac{1}{\Delta}\left\{\frac{a t^{2}}{s} \cdot\left|\begin{array}{cc}a c_{h h} & b\left(C_{h}-\theta\right) \\ -\gamma\left(\theta+c_{h}\right) & 0\end{array}\right|-\frac{b t^{2}}{s} \cdot\left|\begin{array}{cc}a c_{s h} & b\left(r+c_{s}\right) \\ a c_{h h} & b\left(c_{h}-\theta\right)\end{array}\right|\right\}$

where $a=-(\lambda+\gamma(1-\tau / i)), \quad b=-(1-\tau / i)$,

and $\Delta$ is the determinant of the matrix of coefficients of (69) which is positive by the second order conditions. Since the signs of $\left(r+c_{s}\right)$ and $C_{s h}$ are indeterminate, the sign of $s^{2}$ is indeterminate, and so, returning to (58), the sign of $d / d x\{[r(x) s(x)+\theta h(x)-\mu]\}$ is indeterminate. ${ }^{11}$ 
Therefore, for some $\hat{x} \in\left(\tilde{x}, x^{*}\right)$, it may be that $r(\hat{x}) s(\hat{x})+\theta h(\hat{x})-\mu<0$, which would mean that for such $\hat{x}$, land at distance $\hat{x}$ is not zoned for development. In such a situation, "optimal" zoning requires "leapfrog" development. Recall now that the solution of (55) is the solution of the first stage of a two-stage maximization problem. Given $N$, the maximized total property value can be written

$$
\text { (71) } \begin{aligned}
R\left(N, G^{*}\right)=2 \pi & \int_{0}^{\tilde{x}} x[r(x ; N, G *)+\theta \bar{h}(x) / \bar{s}(x)] d x \\
& +2 \pi \int_{\tilde{x}}^{x^{*}} \alpha *(x) x[\bar{r}+\theta h *(x) / s *(x)] d x
\end{aligned}
$$

where $\alpha *(x), h *(x)$ and $s *(x)$ are the maximizers of (55). Then, using (39), the solution for the "optimal". population for Mr. $j$ has the first order conditions

(72) $\quad(1-\tau / 1) W^{2}-T_{N} \Lambda^{j}=0$

where $\quad \tau_{N}=-\tau R_{N} / R$

It does not appear to be possible to compare the populations or aize of the cities for the model of this section with the model of section $C$. As we will see in the next section, with a property tax system neither aggregate zoning nor lot-' and house-size zoning are efficient. 
IV. The Efficlency of Urban Land Use Controls

In our discussion of efficiency, we will confine ourselves to Pareto optimal allocations in which all potential residents attain a utility level of $\bar{U}$. Therefore we need only consider the welfare of current residents and the absentee landlords. 12 The absentee landlords' welfare is an increasing function of the value of their land. In what follows we will assume that $G^{*}$ is given.

The total bid-rent for Mr. j's lot and house (by (34)) is

(73) $\quad r\left(x ; s^{-j}, \bar{h}^{-j}, N, G^{*}\right) s^{-j}+\theta^{-j}=W(N)-t(x)-C\left(G *, s^{-j}, h^{-j}\right)$

From the budget constraint for $\mathrm{Mr} . \mathrm{j}$

$$
c^{j}=W(N)-t(x)+Y^{j}
$$

Since $Y^{j}$ and $C\left(G *, \bar{s}^{j}, \bar{h}^{j}\right)$ are constants, independent of $N, M r . j$ 's welfare is an increasing function of the bid-rent for his lot and house. Thus, since the welfare of the absentee landlords is an increasing function of the bid-rent for their land, the Pareto optimal city maximizes the sum of the total bid-rent for existing residents' lots and houses plus the excess of rents over opportunity cost for the absentee landlords' land (minus the cost of the public good, which is assumed fixed at $\left.G^{*}\right)$. For this city the size of the "pie" to be divided up (between current residents and absentee landlords) is largest. Therefore the Pareto optimal city is independent of the preferences of the current residents. 


\section{A. Constrained Pareto efficlency}

If lot- and house-size zoning are not possible, the constrained Pareto optimal city is given as the solution of

$$
\begin{aligned}
\max _{\{\alpha(x), N\}} 2 \pi \int_{0}^{\tilde{x}} x(W(N)-t(x) & -C(G *, \bar{s}(x)+\bar{h}(x)) d x / \bar{s}(x) \\
& +2 \pi \int_{\tilde{x}}^{\bar{x}} x \alpha(x)(r(x)-\bar{r}) d x
\end{aligned}
$$

subject to:

$$
\text { 1) } u(r(x), \theta, W-t(x))=\bar{U}
$$

11) $0 \leqq \alpha(x) \leqq 1$

$$
\text { iii) } 2 \pi \int_{\tilde{x}}^{\bar{x}} \frac{x \alpha(x) d x}{s(x(x), \theta, \bar{U})}=N-\tilde{N}
$$

where $S(r(x), \theta, \bar{U})$ is the Hicks-compensated demand for land.

$$
r^{2}(x)=-t^{2} / S(x), x>\tilde{x}
$$

This can be posed as an optimal control problem with state variable $\Delta(\mathrm{x})$ and control variable $\alpha(\mathrm{x})$ :

(77)

$$
\max _{\{\alpha(x), N\}} \Delta\left(x^{*}\right)+F(N)
$$

subject to: i) $F(N)=2 \pi \int_{0}^{\widetilde{x}} x(W(N)-t(x)-C(G *, \bar{s}(x), \bar{h}(x)) d x / \bar{s}(x)$

i1) $\Delta^{\prime}(x)=2 \pi x \alpha(x)(x(x)-\bar{x}), x>\tilde{x}$

iii) $0 \leqq \alpha(x) \leqq 1$

$$
\begin{aligned}
& \text { iv) } 2 \pi \int_{\widetilde{x}}^{x^{*}} \frac{x x(x) d x}{s(r(x), \theta, \bar{U})}=N-\widetilde{N} . \\
& \text { v) } r(x) \text { given by } u(r(x), \theta, W-t(x))=\bar{U} .
\end{aligned}
$$


The Hamiltonian for this problem is

(78)

$$
2 \pi x \alpha(x)[\beta(r(x)-\bar{r})-\mu / S(x)]
$$

where $\beta$ is the (constant) costate variable corresponding to the state variable $\Delta$, and $\mu$ is the (constant) multiplier corresponding to the constraint (77) $1 v$.

The first-order conditions for the maximization with respect to the control variable requires

$$
\begin{aligned}
& \alpha(x)=1, \text { if } \beta(x(x)-\bar{x})-\mu / S(x) \geqq 0 \\
& \alpha(x)=0, \text { otherwise. }
\end{aligned}
$$

The first-order conditions for the maximization with respect to the parameter N require

(80) $\quad W^{\prime} \tilde{\mathrm{N}}+2 \pi \int_{\tilde{\mathrm{x}}}^{\tilde{\mathrm{x}}} \mathrm{x} \alpha(\mathrm{x}) \frac{W^{\prime}}{S(x)}\left(\beta+\mu S_{r} / S(x)\right) d x+\mu=0$.

Since $W^{\prime}<0,(80)$ requires $\mu>0$ for a solution with $N>\widetilde{N}$. Finally, the transversality condition requires

$$
\beta\left(r\left(x^{*}\right)-\bar{r}\right)-\mu / S\left(x^{*}\right)=0 \text {. }
$$

Since, $\beta, \mu>0,(81)$ requires $r\left(x^{*}\right)-\vec{r}>0$, i.e., (constrained) efficiency requires restrictive zoning. Rewriting (79),

$$
\begin{aligned}
& \alpha(x)=1, \quad \text { if }(r(x)-\bar{r}) S(x) \geqq \mu / \beta \\
& \alpha(x)=0, \quad \text { otherwise. }
\end{aligned}
$$

Differentiating $(x(x)-\bar{r}) S(x)$,

(83) $\mathrm{d} / \mathrm{dx}[\mathrm{r}(\mathrm{x})-\overline{\mathrm{r}}) \mathrm{S}(\mathrm{x})]=\mathrm{r}^{\prime} \mathrm{S}(\mathrm{x})+(\mathrm{r}(\mathrm{x})-\overline{\mathrm{r}}) \mathrm{S}^{\prime}(\mathrm{x})=-\mathrm{t}^{2}-\frac{(r(x)-\bar{r}) \mathrm{t}^{\prime} \mathrm{S}_{\mathrm{r}}}{\mathrm{s}(\mathrm{x})}$ 
Since $S_{r}<0$, the sign of $d / d x[(r(x)-\bar{r}) S(x)]$ is indeterminate, and so for some $\hat{x} \in\left(\tilde{x}, x^{*}\right)$ it may be the case that $(r(\hat{x})-\bar{r}) S(\hat{x})<\mu / \beta$. Therefore leapfrog development may be required for (constrained) efficiency:

Constrained efficiency requires zoning because of the market failure arising from the fact that migrants will not take into account their effect on the wage rate. Constrained efficiency may require leapfrog development because this market failure results in inefficient pricing in the land market. As we see next, full efficiency requires aggregate and lot-size zoning, but precludes leapfrog development.

B. Unconstrained Pareto efficiency

If lot- and house-size zoning are possible, the Pareto optimal city Is given as the solution of

$$
\begin{aligned}
\max _{\{\alpha(x), s(x),} & \left.h(x), N, x^{*}\right\}, \int_{0}^{\tilde{x}} x(W(N)-t(x)-C(G *, \bar{s}(x), \bar{h}(x)) d x / \bar{s}(x) \\
& +2 \pi \int_{\tilde{x}}^{\bar{x}} \alpha(x) x\left[r\left(x ; s(x), h(x), N, G^{*}\right)-\bar{r}\right] d x
\end{aligned}
$$

subject to

1) $r(x ; s(x), h(x), N, G *)=(W(N)-t(x)-\theta h(x)-$

$$
C(G *, s(x), h(x))) / s(x)
$$

1i) $0 \leqq \alpha(x) \leqq 1$

1i1) $2 \pi \int_{\tilde{\mathrm{x}}}^{\overline{\mathrm{x}}} \frac{\alpha(x) x d x}{s(\mathrm{x})}=\mathrm{N}-\tilde{\mathrm{N}}$ 
Let $\Delta(x)=2 \pi \int_{\widetilde{x}}^{x} \alpha(z) z[r(z ; s(z), h(z), N, G *)-\bar{r}] d z$. Then, as with (65),

(84) can be posed as an optimal control problem with state variable $\Delta(x)$ and dynamics $\Delta^{\prime}=2 \pi(x) \alpha(x) \cdot\left[r\left(x ; s(x), h(x), N, G^{*}\right)-\bar{r}\right]$. The Hamiltonian for the problem is

(85) $\quad \lambda 2 \pi x \alpha(x)[(W(N)-t(x)-\theta h(x)-c(G *, s(x), h(x))) / s(x)-\dot{r}]$ $-\mu 2 \pi x \alpha(x) / s(x)$

The Hamiltonian is to be maximized with respect to the control variables: $\alpha(x), s(x), h(x)$.

The first order conditions for the maximization with respect to the control variables require

$$
\begin{aligned}
& \text { i) } \alpha(x)=1 \text {, if } \lambda(r(x)-\bar{r})-\mu / s \geqq 0 \\
& \alpha(x)=0 \text {, otherwise } \\
& \text { ii) }-\lambda\left(r(x) / s+c_{s} / s\right)+\mu / s^{2}=0 \\
& \text { iii) }-\lambda\left(\theta+c_{h}\right)=0
\end{aligned}
$$

The first order conditions for the control parameter, $N$, require

$$
2 \pi \int_{0}^{\tilde{x}} x W^{\prime}(N) d x / \bar{s}(x)+\lambda 2 \pi j_{0}^{\tilde{x}} x \alpha(x) W^{\prime}(N) d x / s(x)+\mu=0
$$

which, using (84) iii), simplifies to

$$
W^{\prime} \tilde{N}+\lambda W^{\prime}(N-\tilde{N})+\mu=0
$$


The transversality condition requires

$$
\lambda\left[r\left(x^{*}\right)-\bar{r}\right]-\mu / s\left(x^{*}\right)=0
$$

Since $\lambda>0$, by $(88)(\mu / \lambda)>0$. Therefore from $(89)$ we have $r\left(x^{*}\right)-\vec{r}>0$; i.e., efficiency requires restrictive zoning. The first order conditions for housing, (86) iii), require $\theta+c_{h}=0$, i.e., the marginal rate of substitution between housing and consumption be equal to the price of housing, so that house-size zoning is not required for efficiency.

$$
\text { Now consider }(86) i i) \text {. Since } \mu>0, r(x)+c_{s}=\mu / \lambda s(x) \text {, i.e., }
$$
the marginal rate of substitution between land and consumption be greater than the bid-rent for land. Therefore efficiency requires that lot sizes be restricted to be larger than the freely chosen lot sizes at price $r(x)$, given $h(x)$. This requirement arises because of the "externality" of migration (Introduced by $W(N)$ ), causes market fallure in the land market. The efficlent land subsidy is $\mu / \lambda s(x)\left(=-W^{\prime}(N) N / s(x)\right)$.

Now consider (86) i). To show that "leapfrogging" is never efficlent, we must show that $d / d x[\lambda(r(x)-\bar{r})-\mu / s]$ is one-signed.

$$
d / d x[\lambda(r(x)-\tilde{r})-\mu / s]=\lambda r^{\prime}+\mu / s^{2} s^{\prime}
$$

From (84) 1), using (86, ii) and $i i i)$

$$
r^{\prime}=-\left(\mu / \lambda s^{2}\right) s^{\prime}-t^{\prime} / s
$$

Combining (90) and (91),

$$
d / d x[\lambda(r(x)-\bar{r})-\mu / s]=-\lambda t^{\prime} / s \cdot<0
$$

Therefore efficiency precludes "leapfrogging". 
If developers operate collectively, and it is possible for them to bribe the current residents, we would expect that the Pareto optimal allocation would result from market forces, even in the absence of zoning controls. This would be less likely, the less concentrated the development industry, since Cournot behavior by individual developers would not yield a Pareto optimal allocation.

Payments by developers to city governments in the form of interest-free loans, provision of public goods (e.g., school buildings and roads), and outright cash grants, appear to be increasingly common in growing urban areas. Contrary to the usual arguments made by developers, such payments (and development restrictions) may increase efficiency.

Notice that the inefficiency which may arise with a head or property tax is not the result of exercised monopoly power; i.e., the fact that the current residents have control of the whole market is not the source of the inefficiency.

In fact, because of the constraint $U(C, s, G)=\bar{U}$, no monopoly power exists. (Notice that the efficient allocation results if all land is owned by a monopoly developer:) The source of the inefficiency is the tax system.

V. Summary

In this paper we analyzed the properties of allocations of urban land which result from an institutional framework in which the current residents of an urban area can control the zoning of undeveloped land. Although the model we developed assumed a "utility-taking" city, we showed that it is always in the interests of the current residents to impose a restrictive zoning policy. The particular zoning policy which will be chosen depends critically on the way that public good expenditures are financed. However, we showed that the optimal zoning policy given a tax system, and the first best optimal zoning policy are independent of the current residents preferences. The first best optimal 
zoning policy always requires restricting the total amount of land developed, and lot-size restrictions. Furthermore, "optimal" zoning with a property tax, and constrained Pareto optimal zoning may require "leapfrog" development! Somewhat surprisingly, perhaps, the ability of the current residents to control the size of the market, is not, itself, a source of market failure. First best optimality will always require restrictive zoning. Any distortion from first best optimality is the result of the Inefficiency of the tax system, not of exercised market power.

Our "ut1lity-taking" assumption seems valid for small cities, but it is probably not reasonable for large cities, or in jurisdictions where regional government can control the zoning of several municipalities. Therefore it would be useful to relax the utility-taking assumption. Furthermore, the welfare implications of the imposition of restrictive zoning by all small cities in a system of cities have yet to be determined. Finally, a closer examination of the determination of public goods expenditure and its relationohip to fiscal zoning would be enlightening. 


\section{Footnotes}

*

This research was funded by the Ontario Economic Council, whose support we gratefully acknowledge. The views expressed in this paper are exclusively those of the authors. Earlier versions of this paper were presented at the Third Annual Canadian Economic Theory Conference, at the University of Montreal, in May, 1978, and at the Workshop on Analytical Urban Economlcs, Queen's Univers1ty, Kingston Ontar1o, June 1978.

$1_{\text {Recent }}$ literature which has addressed this issue includes the papers In Mills and Oates (1975), Henderson (1977), Ellickson (1977), and Hamilton (1978).

${ }^{2}$ Documentation of the tightening of such controls in American cities is found in Ellickson (1977)。 In Canada, HUDAC has beer concerned with such controls, and has documented them in such studies as Derkowski (1975).

${ }^{3}$ See Derkowskf. (1975), Bourne (1977), Markusen and Scheffman (1977), Ellickson (1977), Scheffman, and Hamilton (1978).

4

${ }^{4}$ This problem is also considered in Stiglitz (1974).

5 For a representative standard model see Solow (1973).

${ }^{6}$ The model developed in Section III will explicitly Include housing.

7 The results are unaffected if there are a number of classes of

identical potential residents, with a large number in each individual class.

${ }^{8}$ For a justification of such an assumption see Hamilton (1978).

Those familiar with the optimal population or optimal city size Iiterature may recognize (16) as a variant of what Flatters, Henderson and Mieszkowsk1 (1974) call the "Henry George Theorem". This can be seen by setting $W(N)=F(N) / N$ in their notation. Other papers developing the Henry George result Include Arnott and Stiglitz (1975), and Stiglitz (1977). 
10

Markusen and Scheffman (R.E.Stud.) show that leapfrog development might be the outcome if all vacant land in a "large" city (utility not exogenous) is owned by a monopoly development industry. See Ohls and Pines (1975) for other arguments on the causes of leapfrogging.

11 Another way of seeing this is that from the budget constraint, $r(x) s(x)+\theta h(x)=W-t(x)-C$, and the sign of $-t^{\prime}-d C / d x$ is indeterminate. ${ }^{12}$ In order to ignore the welfare of the recipients of non-wage income in the $\mathrm{CBD}$, we will assume labourers are paid their average product. 


\section{Bibliography}

Alonso, W. (1960), "A Theory of the Urban Land Market," Papers and Proceedings of the Regional Science Association, 6, 149-157.

Alonso, W. (1964), Location and Land Use (Harvard University Press, Cambridge, Mass .)

Arnott, R., and Stiglitz, J. (1975), "Aggregate Land Rents, Aggregate Transport Costs and Expenditure on Public Goods," mimeo.

Bourne, L. (1977), "The Housing Supply and Price Debate: Divergent Views and Policy Consequences," Centre for Uxban and Community Studies, University of Toronto, mimeo.

Derkowskd, A. (1975), "Costs in the Land Development Process," HUDAC Economic Research Committee.

Ellickson, R. (1977), "Suburban Growth Controls : An Economic and Urban Analysis," Yale Law Journa1, 388-511.

Flatters, F., V. Henderson, and P. Mieskowski (1974), "Public Goods, Efficiency, and Regional Fiscal Equalization," Journal of Public Economics, 99-112.

Hamilton, B. (1978), "Zoning and the Exercise of Market Power," Journal of Urban Economics, 116-130.

Henderson, J. (1977), Economic Theory and the Cities, Academic Press. Margolis, J. (1956), "On Munic1pal Land Policy for Flscal Gains," National Tax Journa1, 247-257.

Markusen, Jo and D. Scheffman (1977), Speculation and Monopoly in Urban Development, University of Toronto Press.

Markusen, J. and D. Scheffman, "Ownership Concentration and Market Power In Urban Land Markets," Review of Economic Studies (forthcoming).

M1118, E. S., (1967), "An Aggregative Model of Resource Allocation in a Metropolitan Area," American Economic Review Papers 57, 197-210. Mills, E. and W. Oates (eds.) (1975), Fisca1 Zoning and Land Use Controls, Heath-Lexington. 
Muth, R. F., (1961), "The Spatial Structure of the Housing Market" Papers and Proceedings of the Regional Science Association, 7, 207-220.

Muth, R. F., (1969), Cities and Housing (Chicago University Press, Chicago). Ohls, J. and Pines, D. (1975), "Discontinuous Urban Development and Economic Efficiency," Land Economics, 224-234.

Pontryagin, Lo (et al) (1962), The Mathematical Theory of Optimal Processes, J. Wiley.

Scheffman, D. (1977), "Some Evidence on the Recent Boom in House and Land Prices," forthcoming in Proceedings of the Conference on Urban Hous Ing Markets, L. Bourne and J. Hitchcock (eds.).

Solow, R。 (1973), "On Equilibrium Models of Urban Location," in M. Parkin (ed.), Essays in Modern Economics, Longmans.

Stiglitz, J. (1977), "The Theory of Local Public Goods," In Economtcs of Public Serv1ces, M. Feldstein and R. Inman (eds.), Macmillan.

White, M. (1975), "F1scal Zoning in Fragmented Metropolitan Areas," In M11ls and Oates (1975).

Wingo, L. (1961a), Transportation and Urban Land (Resources for the Future, Washington, D.C.).

Wingo, L. (1961b), "An Economic Model of the Utilization of Land for Residential Purposes," Papers and Proceedings of the Reglonal Science Association, 7, $191-205$. 